\title{
Routine Iron Supplementation and Anaemia by Third Trimester in a Nigerian Hospital
}

\author{
Adanikin, Abiodun $\mathbf{I}^{1}$, Awoleke, Jacob $\mathbf{O}^{\mathbf{1}}$, Olofinbiyi, Babatunde $\mathrm{A}^{\mathbf{1}}$, Adanikin, \\ Pipeloluwa $\mathrm{O}^{2}$, Ogundare, Omobolanle $\mathrm{R}^{3}$
}

\begin{abstract}
BACKGROUND: Anaemia in pregnancy is associated with adverse maternal and fetal outcome. Unfortunately, in developing countries its prevalence has continued to rise. To improve the situation, iron supplement is routinely prescribed during pregnancy. We therefore examine the impact of the intervention as being currently practised in our clinical setting.

METHODS: In total, 255 prenatal clinic attendees who had more than 8 weeks of prescribed iron supplements were sampled. Data was obtained on their socio-demographic features, haemoglobin concentration at booking, compliance with iron supplements and third trimester haemoglobin value.

RESULTS: Observed iron supplementation compliance rate was 184(72.2\%). There was a significant drop in mean haemoglobin (Hb) concentration between the two time points (booking Hb: 32.56 \pm 2.99 ; third trimester Hb: 31.67 $\pm 3.01 ;$ mean diff: 0.89 $\pm 3.04 ; t=4.673 ; 95 \% C I=0.52-1.27 ; p=\langle 0.001$ ). Anaemia increased from 132(51.8\%) to 150(58.8\%) by the third trimester. Increase in anaemia occurred in both iron-compliant and non-compliant groups. Non-compliance however had higher odds of predicting anaemia by the third trimester (OR: 1.83; 95\% CI: 1.03-3.26; p: 0.04).

CONCLUSION: Although iron supplementation is still a good intervention in developing countries, it is not sufficient to reduce overall prevalence of anaemia by the third trimester. There is a need to look beyond the approach and reinforce the importance of better feeding practices, food fortification and reduced frequency of pregnancies.
\end{abstract}

KEYWORDS: Anaemia, pregnancy, iron supplementation, outcome, food fortification

DOI:http://dx.doi.org/10.4314/ejhs.v25i4.3

\section{INTRODUCTION}

Combating high incidences of maternal morbidity and mortality that is characteristic of low-resource settings has been a daunting task. Ranging from the plague of obstetric haemorrhage, the devastating effects of unsafe abortions and the rampaging trend of unsupervised labour to the scourge of maternal under-nutrition and anaemia, maternal health researchers day-after-day have battled to wrest the woman from preventable deaths.

Anaemia in pregnancy, defined as haemoglobin concentration of less than $11 \mathrm{~g} / \mathrm{dL}$, is a major contributor to maternal morbidity and mortality in the developing world (1). For example, it is estimated that close to $20 \%$ of maternal mortalities are directly linked to anaemia and another $50 \%$ of maternal deaths are associated with it (2). Sadly, more than half of gravid women in these areas have low haemoglobin concentrations and have to grapple with its consequences (3).

Iron deficiency is believed to be the most common cause of anaemia in pregnancy (4). Stemming from poor iron reserve right from birth, inadequate dietary intake of iron, defective iron absorption conferred by helminthic infestations and increased iron requirements due to and breastfeeding has made iron deficiency anaemia

\footnotetext{
${ }^{1}$ Department of Obstetrics and Gynecology, Ekiti State University, Ado-Ekiti, Nigeria

${ }^{2}$ Department of Family Medicine, Ekiti State University Teaching Hospital, Ado-Ekiti, Nigeria

${ }^{3}$ Nursing Unit, Prenatal Clinic, Ekiti State University Teaching Hospital, Ado-Ekiti, Nigeria

Corresponding Author: Abiodun Idowu ADANIKIN, Email: adanikinbiodun@yahoo.com
} 
[IDA] to continue to soar (5).

Multiple control strategies aimed at combating IDA were indeed adopted. Notable ones were enrichment and fortification of food items, and educational interventions to promote dietary changes. Although these were met with some success in developed countries, it was not the same in developing world $(2,6)$. Therapeutic approach in the form of iron supplementation was thus the promising option.

Advocacy for routine supplementation was hinged on the fact that physiological requirement for iron during pregnancy cannot be met by most diets and that even pre-pregnant iron replete women would be in need of iron supplements $(7,8)$. It was therefore suggested that pregnant women should receive iron supplements ranging from 30-120mg daily depending on geographical prevalence of anemia, diagnosis of anaemia and/or available duration for the therapy (9).

However, the recommendation was not without scientific disagreement based on the possibility of excess iron causing polycythaemia, oxidative damage and triggering severe chronic diseases $(6,10)$. Therefore, blanket administration of iron during pregnancy was not universally accepted though it is a popular practice in developing countries where it is most needed.

Again, emerging evidences on the effectiveness of the prescribed iron supplements have been inconclusive. While some reports found significant contribution of the approach to improving maternal haemoglobin concentration and pregnancy outcome $(11,12)$, others have refuted the claim $(13,14)$. Thus, considerable amount of information remains to be learnt about the influence of this approach on maternal anemia especially in African settings.

Therefore, this research sets out to examine the impact of routine iron supplementation on maternal anemia by third trimester in our environment.

\section{METHODS AND PATIENTS}

Study setting: This observational study was conducted at the department of Obstetrics and Gynaecology of Ekiti State University Teaching Hospital (EKSUTH), Ado-Ekiti, southwest Nigeria between February 1 and April 30, 2014. The hospital is a tertiary health facility that provides comprehensive maternity services, accepts referral of high risk pregnancies and manages complicated labour cases from primary and secondary health centres within the geopolitical region. Its average delivery rate is 2,500 per year.

The obstetrics unit of EKSUTH operates a two firm system; one firm runs its prenatal clinic on Wednesday while the other does so on Friday. As largely practised in Nigeria, depending on when prenatal registration was done, our patients are usually seen every four weeks until twentyeight weeks of gestation, then fortnightly until thirty-six weeks, and thereafter weekly until delivery. Some patients are, however, seen more frequently when clinically indicated.

Routinely at booking, screening and control/treatment of common ailments such as HIV infection, helminthic infestation, malaria, etc are done. In addition, the obstetrics unit administers malaria chemoprophylaxis (Intermittent Preventive Therapy) appropriately using Sulphadoxine/Pyrimethamine combination which is given at least twice with a minimum of 4weeks interval between 16 weeks and 36 weeks gestational age. Aside these measures, in the course of prenatal care, overt development of features of malaria/helminthic infestation are promptly treated. Due to subsisting high prevalence of anaemia in pregnancy within the area, we practise blanket prescription of $120 \mathrm{mg}$ of elemental iron and 5mg of folic acid as daily supplements for all pregnant women.

Sampling procedure: Using a previous report of $20 \%$ prevalence of anaemia in the last trimester from Calabar, Nigeria (15), we calculated that a sample size of 246 women would be needed for an acceptable error margin of 5\%, standard normal deviate of 1.96 and a confidence interval of $95 \%$. Though unlikely, we decided to sample 255 participants to make allowance for attrition.

Eligible women were prenatal clinic attendees who registered at gestational age (GA) $\leq 26$ weeks and whose pregnancies progressed to reach 35-36 weeks when recruited for the study. Those whot did not meet the eligibility criteria and patients with multiple gestation, haemoglobinopathy or chronic medical illnesses were excluded. Eligible women were sequentially recruited after an informed written consent in the order on clinic attendance until the sample size was reached. 
Recruitment was at GA of 35-36 weeks, and participants were administered a semi-structured questionnaire by trained resident doctors. The questionnaire was used to obtain information on patients' socio-demographic characteristics, compliance with prescribed iron supplementation, medication side effects (if any), possible reasons for non-compliance, etc. Venous blood specimen was then collected from them for estimation of their haemoglobin concentration at that GA. Information about the haemoglobin concentration of each participant at the time of prenatal care booking was obtained from the hospital files and respectively entered into the study proforma.

In this study, hemoglobin value of less than $11.0 \mathrm{~g} / \mathrm{dL}$ was considered to be anaemia in pregnancy (1). The measurement of haemoglobin at booking and at third trimester (35-36 weeks) was made by spectrophotometer techniques (oxyhaemoglobin method). We defined compliance as the extent to which a patient acts in accordance with the prescribed dose and interval of the medication (16). Adherence of $80 \%$ or more was regarded as being compliant.

Statistical analysis: All relevant data was entered into Statistical Package for Social Sciences (SPSS) version 17. The computer software was used to generate the frequency table, and the results were tested for significance using paired $t$ test, chi square test $\left(\chi^{2}\right)$ or logistic regression analysis as appropriate. Level of significance $(\alpha)$ was set at 0.05 .

Ethical consideration: The research was conducted in accordance with prevailing ethical principles. The approval for the study was obtained from the Ekiti State University Teaching Hospital Ethics and Research Committee.

\section{RESULT}

Table 1 summarizes the socio-demographic characteristics of respondents. Fifteen $(5.9 \%)$ were $\leq 24$ years old, while $53(20.8 \%)$ were $\geq 35$ years old; $187(73.3 \%)$ were between the ages of 25 and 34 years. Only 23(9.0\%) were singles, whilw others were married. Thirty five (13.7\%) respondents had primary education, 93(36.5\%) had secondary education and $127(49.8 \%$ ) attended tertiary schools.
Most of the women, 159(62.4\%), were involved in semi-skilled jobs; less than a fifth had skilled jobs. Out of the studied population, $95(37.3 \%)$ were primigravida, and $160(62.7 \%)$ were multigravida. Thirty0seven $(14.5 \%)$ had unplanned pregnancy.

Table 1: Demographic features of participants

\begin{tabular}{ll}
\hline Variables & Frequency (\%) \\
\hline Age (years) & $15(5.9)$ \\
$\leq 24$ & $187(73.3)$ \\
$25-34$ & $53(20.8)$ \\
$\geq 35$ & \\
Religion & $237(92.9)$ \\
Christianity & $18(7.1)$ \\
Islam & \\
Tribe & $222(87.1)$ \\
Yoruba & $30(11.8)$ \\
Igbo & $3(1.2)$ \\
Hausa & \\
Marital status & $23(9.0)$ \\
Single & $232(91.0)$ \\
Married & \\
Educational level & $35(13.7)$ \\
Primary & $93(36.5)$ \\
Secondary & $127(49.8)$ \\
Tertiary & \\
Occupation & $54(21.2)$ \\
Unskilled & $159(62.4)$ \\
Semi-skilled & $42(16.5)$ \\
Skilled & \\
Gravidity & $95(37.3)$ \\
Primigravida & $160(62.7)$ \\
Multigravida & \\
Pregnancy Planned & \\
Yes & $218(85.5)$ \\
No & $37(14.5)$ \\
\hline &
\end{tabular}

Table 2 shows that $132(51.8 \%)$ had anaemia at prenatal booking visit, but by third trimester, $150(58.8 \%)$ were anaemic. Compliance with iron supplementation was found in $184(72.2 \%)$ of the prenatal care attendees. Among the 71(27.8\%) women who did not comply with the iron prescription, $32(45.1 \%)$ related reason to forgetfulness, $29(40.8 \%)$ did not use it because of side effects (gastrointestinal upsets, constipation and nausea), while others attributed non-usage to fear of harm to baby or negligence. 
Table 2: Anaemia and iron supplementation compliance

\begin{tabular}{ll}
\hline Variable & Frequency (\%) \\
\hline Anaemic at booking?; $n=255$ & $132(51.8)$ \\
$\quad$ Yes & $123(48.2)$ \\
$\quad$ No & \\
Anaemic by third trimester?; $n=255$ & $150(58.8)$ \\
$\quad$ Yes & $105(41.2)$ \\
No & \\
Compliant with iron prescription?; $n=255$ & $184(72.2)$ \\
Yes & $71(27.8)$ \\
No & \\
Reasons for non-compliance, $n=71$ & $32(45.1)$ \\
Forgetfulness & $29(40.8)$ \\
Side effects & $10(14.1)$ \\
Others & \\
\hline
\end{tabular}

Further analysis demonstrates that out of 132 respondents who were anaemic at the booking visit, 39(29.5\%) did not comply with iron supplementation regimen (Table 3). Among those who were non-anaemic at booking, 32(26.0\%) were also non-compliant with the prescribed iron.

Table 3: Pattern of compliance with iron supplementation by anaemic status at booking

\begin{tabular}{l|c|c|c}
\hline \multirow{2}{*}{ Variable } & \multicolumn{2}{|c|}{ Iron compliant } & \multirow{2}{*}{ Total } \\
\cline { 2 - 3 } & Yes & No & \\
\hline Anaemic at booking? & & & $132(100)$ \\
Yes & $93(70.5)$ & $39(29.5)$ & $123(100)$ \\
No & $91(74.0)$ & $32(26.0)$ & \\
\hline
\end{tabular}

By the third trimester, 101(76.5\%) who had anaemia at booking were still anaemic while 49(39.8\%) who were previously not anaemic

Table 4: Relationship between anaemia at booking and at third trimester

\begin{tabular}{l|c|c|c}
\hline \multirow{2}{*}{ Variable } & \multicolumn{2}{|c|}{ Anaemic by third trimester } & \multirow{2}{*}{ Total } \\
\cline { 2 - 3 } & Yes & No & \\
\hline Anaemic at booking? & $101(76.5)$ & $31(23.5)$ & $132(100)$ \\
Yes & $49(39.8)$ & $74(60.2)$ & $123(100)$ \\
No & & & \\
\hline
\end{tabular}

The mean haemoglobin concentration at booking was $32.56 \pm 2.99$, and at third trimester it was 31.67 \pm 3.01 . Paired $\mathrm{t}$ test analysis showed a significant drop in mean haemoglobin concentration between this two time points (mean diff: $0.89 \pm 3.04 ; \mathrm{t}=4.673 ; 95 \% \mathrm{CI}=0.52-1.27 ; \mathrm{p}=$ $<0.001)$. Increased in prevalence of anaemia was observed in both iron compliant and noncompliant groups. Whereas 93(50.5\%) of the became anaemic (Table 4). Overall, an increase of $7 \%$ in prevalence of anaemia was observed. sampled subset who were compliant with iron had anaemia at booking, the number increased to $101(54.9 \%)$ by third trimester. Also, among the non-compliant subset, anaemia increased from $39(54.9 \%)$ at booking to $49(69.0 \%)$ by third trimester. Further analysis (Table 5), however, showed that the non-compliance had higher odds of predicting anaemia by the third trimester (OR: 1.83; 95\% CI: 1.03-3.26; p: 0.04). 
Table 5: Regression analysis of non-compliance with iron medication and anaemia by third trimester

\begin{tabular}{|c|c|c|c|c|c|c|}
\hline \multirow[t]{2}{*}{ Variable } & \multicolumn{2}{|c|}{ Anaemia } & \multirow[t]{2}{*}{ Total } & \multirow[t]{2}{*}{ Odd ratio } & \multirow[t]{2}{*}{$95 \% \mathrm{CI}$} & \multirow[t]{2}{*}{$P$ value } \\
\hline & Yes & No & & & & \\
\hline \multicolumn{7}{|l|}{ Non-compliant } \\
\hline Yes & $49(69.0)$ & $22(30.9)$ & $71(100)$ & 1.83 & $1.03-3.26$ & $0.040 *$ \\
\hline No & $101(54.9)$ & $83(45.1)$ & $184(100)$ & 1.00 & & \\
\hline
\end{tabular}

*significant at $\mathrm{p}<0.05$

Non-compliance with iron supplementation was more among respondents who were $<24$ years old, muslims, married, with secondary level of education, unskilled, multigravida and with unplanned pregnancies. However, none of the socio-demographic features had statistical significance in predicting non-compliance with prenatal iron supplementation (Table 6).

Table 6: Predictor of non-compliance with iron supplementation

\begin{tabular}{|c|c|c|c|c|c|c|}
\hline \multirow[t]{2}{*}{ Variable } & \multicolumn{2}{|c|}{ Non-compliant } & \multirow[t]{2}{*}{ Total } & \multirow{2}{*}{$\begin{array}{l}\text { Adjusted } \\
\text { odd ratio }\end{array}$} & \multirow[t]{2}{*}{$95 \%$ CI } & \multirow[t]{2}{*}{$P$ value } \\
\hline & Yes & No & & & & \\
\hline \multicolumn{7}{|l|}{ Age (years) } \\
\hline$\leq 24$ & $5(33.3)$ & $10(66.7)$ & $15(100)$ & 1.00 & & \\
\hline $25-34$ & $55(29.4)$ & $132(70.6)$ & 187(100) & 1.25 & $0.41-3.55$ & 0.749 \\
\hline$\geq 35$ & $11(20.8)$ & $42(79.2)$ & $53(100)$ & 1.94 & $0.56-6.52$ & 0.311 \\
\hline \multicolumn{7}{|l|}{ Religion } \\
\hline Christianity & $64(27.0)$ & $173(73.0)$ & $237(100)$ & 1.75 & $0.66-4.51$ & 0.278 \\
\hline Islam & $7(38.9)$ & 11(61.1) & $18(100)$ & 1.00 & & \\
\hline \multicolumn{7}{|l|}{ Tribe } \\
\hline Yoruba & $59(26.6)$ & $163(73.4)$ & $222(100)$ & 0.39 & $0.03-5.20$ & 0.299 \\
\hline Igbo & $12(40.0)$ & $18(60.0)$ & $30(100)$ & 0.21 & $0.01-3.03$ & 0.170 \\
\hline Hausa & $0(0)$ & $3(100)$ & $3(100)$ & 1.00 & & \\
\hline \multicolumn{7}{|l|}{ Marital status } \\
\hline Single & $5(21.7)$ & $18(78.3)$ & $23(100)$ & 1.00 & & \\
\hline Married & $66(28.4)$ & $166(71.6)$ & $232(100)$ & 0.74 & $0.25-1.92$ & 0.494 \\
\hline \multicolumn{7}{|c|}{ Educational level } \\
\hline Primary & $11(31.4)$ & $24(68.6)$ & $35(100)$ & 1.00 & & \\
\hline Secondary & $32(34.4)$ & $61(65.6)$ & $93(100)$ & 0.89 & 0.38-1.99 & 0.750 \\
\hline Tertiary & $28(22.0)$ & $99(78.0)$ & $127(100)$ & 1.64 & $0.72-3.67$ & 0.250 \\
\hline \multicolumn{7}{|l|}{ Occupation } \\
\hline Unskilled & $16(29.6)$ & $38(70.4)$ & $54(100)$ & 0.66 & $0.26-1.64$ & 0.364 \\
\hline Semi-skilled & $46(28.9)$ & 113(71.1) & $159(100)$ & 0.69 & $0.30-1.50$ & 0.332 \\
\hline Skilled & $9(21.4)$ & $33(78.6)$ & $42(100)$ & 1.00 & & \\
\hline \multicolumn{7}{|l|}{ Gravidity } \\
\hline Primigravida & $24(25.3)$ & 71(74.7) & $95(100)$ & 1.00 & & \\
\hline Multigravida & $47(29.4)$ & 113(70.6) & $160(100)$ & 0.82 & $0.46-1.44$ & 0.479 \\
\hline \multicolumn{7}{|l|}{ Pregnancy } \\
\hline \multicolumn{7}{|l|}{ Planned } \\
\hline Yes & $58(26.6)$ & $160(73.4)$ & $218(100)$ & 1.51 & $0.72-3.10$ & 0.285 \\
\hline No & 13(35.1) & $24(64.9)$ & $37(100)$ & 1.00 & & \\
\hline
\end{tabular}




\section{DISCUSSION}

This study found out that after controlling malaria/helminthic infestation, a drop in mean haemoglobin concentration and $7 \%$ increase in prevalence of anaemia occurred among prenatal care attendees despite being on iron supplementation for more than 8 weeks with a compliance rate of $72.2 \%$. Though statistical evidence shows that non-compliance with iron therapy would predict anaemia in the third trimester, compliance among three-quarter of the respondents was not sufficient to reduce the overall prevalence of anaemia. Surprisingly, increase in anaemia was observed in both compliant and non-compliant subsets of prenatal clinic attendees.

Some researchers have called to questioning the effectiveness of iron supplement in reducing prevalence of anaemia in all populations of pregnant women $(14,17)$. Though others basically argued that its ineffectiveness may be attributable to low compliance (18), a reappraisal of this assertion may be necessary in that in our study iron supplements have failed to improve anaemia in the presence of good compliance.

Usually, due to poverty with attending inability to afford balanced diet and the problem of 'too frequent and too many pregnancies', women in low-resource areas tend to conceive with severely depleted iron store (5). Compounded by the habit of late prenatal care booking which allows less time for anemia correction (19), it is obvious that in resource-scarce settings we need to look beyond iron supplements as the only 'saviour'.

It could be that the supplementation can reduce the extent of iron depletion in the third trimester (20), but for women who became pregnant with very low or no iron stores, the approach may not be sufficient to prevent anemia by third trimester. Cogswell et al found that the effect of iron supplementation on anaemia by the third trimester is not significant (13).

Certainly, some research works have demonstrated positive influence of iron supplements on haemoglobin concentration by the last trimester $(11,12)$. However, the complex interplay of clinical, cultural, societal and economic settings may not make that finding generalizable.
The World Health Organization recommends a $30 \mathrm{mg}$ daily dose of elemental iron in a setting where prevalence of anemia in pregnancy is $<40 \%$ and $60 \mathrm{mg}$ daily in places with higher prevalence. Where anaemia is diagnosed or the available duration for supplements will be $<6$ months, a daily dose of $120 \mathrm{mg}$ of elemental iron is suggested (9). In our setting, because anemia is of severe public health importance and duration available for iron supplements is often $<6$ months, we routinely give $120 \mathrm{mg}$ of elemental iron to all prenatal care attendees.

In a submission by the Centers for Disease Control and Preventions (CDC), it noted that higher doses of iron do not necessarily provide greater benefit to pregnant women in correcting anaemia (21). This is possibly true in our observation because the high dose has not effectively reduced overall anemia prevalence. There may also be a need to exercise caution because of adverse effects that such dose may have (10).

Compliance rate among the gravid women was higher than $37.2 \%$ observed in Oyo state, Nigeria eight years ago (22). The variation can be attributed to passage of time, study location and the degree of enlightenment of participants. Whereas the aforementioned study was conducted at primary health care level, ours was done at a tertiary health facility which likely skewed participants towards more educated ones. It is therefore possible that reduced compliance and worse prevalence of anaemia at third trimester would be recorded at lower levels of care. Our compliance rate, however, is comparable with studies from India and Senegal where compliance was $65 \%$ and $69 \%$ respectively $(23,24)$.

Forgetfulness and perceived side-effects accounts mostly for non-compliance; it is similar with what was found by Mithra et al (23). More provision of clear instruction on health benefits of the supplementation and tapering of the dose could enhance compliance.

This study is not without social desirability bias. There is a tendency that since compliance was self-reported, actual rate may be lower. Compliance is best measured by continuous direct observation that therapies are taken (25), a process that is impracticable in this circumstance. Although there is still a tendency of overestimation of adherence to therapy by pill 
counts (25), for future studies, adjoining it as a measure of compliance will be suggested.

Predicting who will not comply with iron supplementation was difficult as none of the socio-demographic features was associated with non-compliance. Some studies, however, found that non-compliance was more among singles, teens and increasing maternal age $(22,23)$.

It is uncertain if weekly iron supplementation will produce similar/better compliance and therapeutic effects in our environments as compared to daily regimen, but considering the stage of our socio-cultural evolvement, it may produce a lower compliance. However, it is worth investigating. Also, comparison of the impact of slow iron gastricdelivery system to high daily elemental iron doses in low-income settings can be researched into.

More needs to be learnt about how to safeguard pregnant women in resource-scarce settings from going into delivery process with suboptimal hemoglobin concentration. It is evident that dependence on prenatal iron supplementation may not be the sole solution. There is a need to look beyond the approach and reinforce the importance of better feeding practices, food fortification and reduced frequency of pregnancies.

\section{REFERENCES}

1. Worldwide prevalence of anaemia 1993-2005. WHO Global Database on Anaemia. Geneva: World Health Organization; de Benoist B, McLean E, EgliI, Cogswell M [http://whqlibdoc.who.int/publications/2008/9 789241596657_eng.pdf]. Accessed June 2014

2. Anand T, Rahi M, Sharma P, Ingle GK. Issues in prevention of iron deficiency anemia in India. Nutrition 2014; 30:764-770.

3. WHO/UNICEF/UNU. Iron deficiency anaemia assessment, prevention, and control: a guide for programme managers. Geneva, World Health Organization, 2001. URL address:

http://www.who.int/nutrition/publications/en/i da_assessment_prevention_control.pdf. Accessed June 2014.

4. Nyuke RB, Letsky EA. Etiology of anaemia in pregnancy in South Malawi. Am J Clin Nutr 2000; 72: 247-256.
5. Brabin BJ, Hakimi M, Pelletier D. 2001. An Analysis of Anemia and Pregnancy-Related Maternal Mortality. J Nutr.131(2): 604S-615S

6. Beard JL. Effectiveness and strategies of iron supplementation during pregnancy. Am J Clin Nutr 2000; 71(Suppl): 1288S-1294S

7. Pritchard JA, Whalley PJ, Scott DE. The influence of maternal folate and iron deficiency on intrauterine life. Am J Obstet Gynecol 1969;104:388-392.

8. Bothwell TH. Iron requirements in pregnancy and strategies to meet them. Am J Clin Nutr 2000, 72(1Suppl): 257S-264S

9. WHO. Guideline: Daily iron and folic acid supplementation in pregnant women. Geneva, World Health Organization, 2012.

10. Gutteridge, John MC. Iron and free radicals. In: Hallberg L, Asp N-G, eds. Iron nutrition in health and disease. London: John Libbey \&Co, 1996:239-246.

11. Yakoob MY, Bhutta ZA. Effect of routine iron supplementation with or without folic acid on anemia during pregnancy. BMC Public Health 2011; 11(Suppl 3): S21

12. Villar J, Merialdi M, Gulmezoglu AM, Abalos E, Carroli G, Kulier R, et al. Nutritional interventions during pregnancy for the prevention or treatment of maternal morbidity and preterm delivery: an overview of randomized controlled trials. J Nutr 2003, 133(5 Suppl 2):1606S-1625S

13. Cogswell ME, Parvanta I, Ickes L, Yip R, Brittenham GM. Iron supplementation during pregnancy, anaemia, and birth weight: a randomized controlled trial. Am J Clin Nutr 2003; 78:773-781.

14. Perry GS, Yip R, Zyrkowski C. Nutritional risk factors among low income pregnant US women: the CDC Pregnancy Nutrition Surveillance System, 1979 through 1993. Semin Perinatol 1995; 19: 211-221.

15. Okafor IM, Asemota EA, Antai AB, Usanga EA. Prevalence of Iron Deficiency Anaemia among Pregnant Women in Calabar, Cross River State Nigeria. J Pharm Biol Sci. 2013; 7(2): 60-64.

16. Cramer JA, Roy A, Burrell A, Fairchild CJ, Fuldeore MJ, Ollendorf DA, Wong PK. Medication compliance and persistence: terminology and definitions. Value Health 2008; 11(1): 44-47. 
17. Thompsen JK, Prien-Larsen JC, Devantier A, Fogh-Anderson N. Low dose iron supplementation does not cover the need for iron during pregnancy. Acta Obstet Gynecol Scand 1993;72:93-98.

18. Schultink W. Iron supplementation: compliance of target groups and frequency of tablet intake. Food Nutr Bull 1996;17:22-26

19. Idowu OA, Mafiana CF, Sotiloye D. 2005. Anaemia in pregnancy: a survey of pregnant women in Abeokuta, Nigeria. Afr Health Sci. 5(4): 295-299.

20. Svanberg B, Arvidsson B, Norrby A, Rybo G, Solvell L. Absorption of supplemental iron during pregnancy - a longitudinal study with repeated bone-marrow studies and absorption measurements. Acta Obstet Gynecol Scand 1976; 48 (Suppl):87-108.

21. Centers for Disease Control and Prevention. CDC report: recommendations to prevent and control iron deficiency in the United States. MMWR Morb Mortal Wkly Rep 1998; 47:129.

22. Dairo MD, Lawoyin TO. Demographic factors determining compliance to iron supplementation in pregnancy in Oyo State, Nigeria. Nig J Med 2006; 15(3): 241-244.

23. Mithra P, Unnikrishnan B, Rekha T, Nithin K, Mohan K, Kulkarni V, et al. Compliance with iron-folic acid (IFA) therapy among pregnant women in an urban area of south India. Afr Health Sci. 2013;13(4):880-885.

24. Seck BC, Jackson RT. Determinants of compliance with iron supplementation among pregnant women in Senegal. Public Health Nutr. 2008;11(6):596-605.

25. Cramer JA, Mattson RH, Prevey ML, Scheyer RD, Ouellette VL. How often is medication taken as prescribed? A novel assessment technique. JAMA 1989;261(22): 3273-3277. 